\title{
Welcome to new ideas and farewell to old friends
}

Endoscopic ear surgery is gaining popularity. This issue contains a study that compares the costs of endoscopic versus open surgery for cholesteatoma in the context of an Australian private hospital. ${ }^{1}$ The results were favourable for the endoscopic method. This conclusion is likely to be more widely applicable, and endoscopic surgery has been the subject of several recent Journal of Laryngology \& Otology articles. ${ }^{2,3}$

Eustachian tube dysfunction or glue ear are all too common sequelae after radiotherapy to the nasopharynx. In this issue, there is a study from Japan which shows that this phenomenon, as judged by sonotubometry, seems to be dependent on a critical amount of radiation delivered to the relevant area. ${ }^{4}$ This may not be particularly surprising, on first principles, but may help guide radiotherapy regimens if the findings are finessed and clarified.

There has been a trend to incorporate corticosteroid preparations into saline nasal douches in patients with chronic rhinosinusitis with polyposis, especially recalcitrant cases. This off-licence usage has been investigated by a team from Queensland who examined efficacy (using the Sino-Nasal Outcome Test 22 (SNOT-22)) and evidence of urinary cortisol level disturbance. ${ }^{5}$ Fortunately, the investigators found no significant cortisol upset, and there was significant benefit as judged by the SNOT-22. This may help allay fears surrounding the practice. With increasing interest in the role of biofilms, how best to use a douche and what to use has lots of mileage. ${ }^{6}$

For several years, we have had the pleasure of collaborating with the Australian Society of Otolaryngology, Head and Neck Surgery (ASOHNS) in publishing their twice-yearly journal as a supplement of The Journal of Laryngology \& Otology. This has been a fruitful liaison, and we are grateful to the ASOHNS administrative staff (particularly Lorna Watson), Cambridge University Press, the Australian editors (Simon Carney and Richard Harvey), reviewers and contributors for making this an interesting addition to the usual stable of The Journal. We have recently learned that the ASOHNS aims to alter its publication model in 2018, and we wish them well in this new and exciting venture. In the interim, the existing accepted papers in our system from Australian authors will be incorporated into the next few issues of the main journal.

EDWARD FISHER

ROBIN YOUNGS

MUSHEER HUSSAIN

JONATHAN FISHMAN

Senior Editors

\section{References}

1 Patel N, Mohammadi A, Jufas N. Direct cost comparison of totally endoscopic versus open ear surgery. J Laryngol Otol 2018;132:122-28

2 Clark M. Endoscopic ear surgery in the ear camp setting; forward thinking or folly? J Laryngol Otol 2018;132:68-70

3 Mitchell S, Coulson C. Endoscopic ear surgery: a hot topic? J Laryngol Otol 2017;131:117-22

4 Akazawa K, Doi H, Ohta S, Terada T, Fujwara M, Uwa N et al. Relationship between Eustachian tube dysfunction and otitis media with effusion in radiotherapy patients. J Laryngol Otol 2018;132:111-16

5 Dawson B, Gutteridge I, Cervin A, Robinson D. The effects of nasal lavage with betamethasone cream post-endoscopic sinus surgery: clinical trial. J Laryngol Otol 2018;132:143-49

6 Ramakrishnan Y, Shields RC, Elbadawey MR, Wilson JA. Biofilms in chronic rhinosinusitis: what is new and where next? J Laryngol Otol 2015;129:744-51 